\title{
El Estado faccioso en la argentina. Corrupción de principios, corrupción de las instituciones
}

\section{The Factious State in Argentina. Corruption of Principles, Corruption of Institutions}

\author{
Hugo Quiroga ${ }^{1}$ \\ Universidad Nacional de Rosario (Argentina)
}

Recibido: 06-09-18

Aprobado: 28-09-18

\section{Resumen}

Este artículo analiza la democracia argentina en su trama de corrupción, con todo lo que tiene de común $-\mathrm{y}$ de distinto- con respecto a otros regímenes democráticos de Latinoamérica y Europa. Las respuestas nos llevan a pensar el presente desde viejas y nuevas categorías. En el trasfondo de esta discusión asoman ciertos nudos teóricos y prácticos con los que enfrentamos al problema democrático arraigado en la corrupción. Desde la instauración democrática en 1983 se pueden distinguir dos formas diferentes de corrupción en la cumbre del poder. El gobierno de Carlos Menem, de diez años de duración, y los gobiernos del matrimonio Kirchner, que permanecieron 12 años en el poder. De estas dos experiencias distintas pondremos el acento en ese entramado de corrupción institucional que llamamos Estado faccioso.

Palabras-clave: Corrupción, democracia, Estado, facciones, principios, instituciones

\footnotetext{
${ }^{1}$ (haquiroga@fibertel.com.ar) Doctor en Filosofía por la Universidad de las Islas Baleares. Profesor e investigador de la Universidad Nacional de Rosario y de la Universidad Nacional del Litoral, Argentina. Sus investigaciones están abocadas a la democracia, la ciudadanía, la representación, el espacio público. Sus libros más destacados son: La Argentina en emergencia permanente (Edhasa, 2005); La República desolada. Los cambios políticos en la Argentina. 2001-2009 (Edhasa, 2010); Democracia delegativa (Prometeo, 2011), coeditado con G. 'Donnell y O. Iazzetta); La democracia que no es. Política y sociedad en la Argentina. 1983-2016 (Edhasa, 2016).
} 


\begin{abstract}
This article is intended to analyse Argentinian democracy in its corruption, taking into account everything that it has in common- and all its differencesregarding other democratic regimes in Latin America and Europe. The answers lead us to think about the present from both old and new categories. Deep inside this discussion some theoretical and practicalissues can be spotted with which we have to face the democratic problem linked to corruption. Since the democratic establishment in 1983 two different forms of corruption can be distinguished in the highest positions of power. For instance the government of Carlos Menem, which was as long as ten years of duration and the governments of the Kirchner couple, who were on power for twelve years. From these two different experiences we will make emphasis on the institutional corruption that we call factious State.
\end{abstract}

Key-words: Corruption, democracy, State, factions, principles, institutions.

\title{
Introducción
}

Las extendidas incriminaciones de corrupción en los ámbitos políticos, gubernamentales y privados componen la alterada e incierta realidad contemporánea. La crisis de credibilidad pública que afecta a los partidos políticos se ha instalado en la mayoría de las sociedades occidentales, lo que abre un vacío político en el que se muestra la falta de una instancia mediadora entre el nivel del individuo y el del Estado.

A comienzo de los años noventa del siglo XX tomaron estado público las vinculaciones del Estado italiano y los políticos con la mafia. Bettino Craxi, primer ministro y líder socialista fue acusado y condenado por corrupción, a través de una investigación del fiscal Antonio Di Pietro conocida como Mani Pulite; en Alemania con posterioridad, el financiamiento político ilegal terminó con la figura de Helmut Kohl; en Brasil, el presidente Collor de Melo fue separado de su cargo por las acusaciones de corrupción; la descomposición de los sistemas políticos en Perú y Venezuela, donde la corrupción no estuvo ausente, llevó al derrumbe de los partidos tradicionales.

En América latina, por ejemplo, varios jefes de Estado han sido condenados por corrupción o bien han sido destituidos. Arnaldo Alemán continúa en la cárcel en Guatemala, y Luis González Macchi permaneció 12 años en prisión. En Perú Ollanta Humada está en la cárcel, y Alberto Fujimori sufrió una condena de diez años y fue liberado, mientras que Alejandro Toledo está prófugo. En 1996 Carlos Andrés Pérez dos veces presidente de Venezuela 
fue condenado a dos años y cuatro meses de prisión. De manera más reciente, en Brasil, el fiscal Sérgio Moro condujo una investigación conocida como Lava Jato caracterizada como una corrupción transnacional, y en ese proceso Lula da Silva recibió una condena a 12 años que ha sido apelada, en tanto el ex vicepresidente de Argentina Amado Boudou recibió una condena de 5 años y seis meses de prisión en 2018, y el ex presidente de Uruguay Raúl Sendic está procesado.

Con el gobierno de Carlos Menem en Argentina, también en los años noventa, surgieron escándalos de corrupción en momentos en que se iniciaba la reforma del Estado y la política de privatizaciones. El ex presidente fue condenado en dos causas, sus sentencias fueron apeladas y en la actualidad se espera un fallo de la Corte Suprema. El tema de la corrupción se instaló en la conciencia pública a fines de los años noventa y comenzó a figurar en el tercer lugar de las preocupaciones de los argentinos hasta alcanzar el primer puesto en marzo y junio de 1992. En poco tiempo fue desplazado de ese lugar por la gravedad de un fenómeno que atravesó los diez años de gobierno menemista, el desempleo; fenómeno que persiste y que se ha acrecentado en la actualidad.

En ese decenio, la sociedad argentina no salía de su asombro, ante lo que vislumbraba era sólo el comienzo de un escándalo político, cuando oyó decir al dirigente sindical Luis Barrionuevo (hombre cercano al presidente Menem) y titular de la Administración Nacional del Seguro de Salud (que tenía a su cargo cifras millonarias correspondientes a las obras sociales sindicales), que "en este país la plata no se hace trabajando", para luego describir cómo han ganado dinero algunos sindicalistas. La frase memorable tenía un corolario: "Si queremos que este país se arregle tenemos que dejar de robar dos años". En la misma ocasión en que reveló el método con que se hace fortuna, Barrionuevo reconoció además haber aportado en su momento un millón de dólares a la campaña electoral del entonces candidato Carlos Menem, levantando suspicacias contra la propia imagen del jefe de Estado.

Los hechos de corrupción señalados - a simple título informativo- y las declaraciones de Barrionuevo, que no fue convocado de oficio por ningún juez, ponen en evidencia los límites de la responsabilidad política de los gobernantes y el endeble interés de la justicia por investigar y avanzar en el camino de la moralización política como superación de la corrupción. Fueron principalmente los jueces federales designados por Menem los que desprestigiaron el poder judicial y conformaron una justicia complaciente con el poder.

Desde esos escándalos de corrupción tan inquietantes, pasando por las coimas en el Senado durante el gobierno de la Alianza en el año 2000, hasta el descubrimiento de una red de corrupción en el período kirchnerista, la sociedad argentina se enfrenta ante una situación desconocida que la lleva a la negatividad extrema. Lo que está sucediendo es verdaderamente inédito en su historia, 
desde el momento en que tomó estado público los "cuadernos de las coimas". Son ocho cuadernos que registran las coimas millonarias vinculadas a empresas de la construcción y del sector energético, que fueron redactados por el chofer, Oscar Centeno, que transportaba bolsas y valijas con millones de dólares hasta la Quinta de Olivos, sede de la residencia presidencial, y a la propia casa del matrimonio Kirchner. El chofer cumplía su tarea junto a funcionarios de alto nivel del ministro de Planeamiento Julio De Vido, hoy detenido después que se le retiró el fuero como diputado nacional. Escritos de manera minuciosa y obsesiva, durante diez años, los cuadernos de Centeno han producido una sisma en sectores de la dirigencia política y del empresario, que roza a algunos jueces. Es la mayor causa de corrupción conocida hasta ahora en la Argentina, que cuenta con un gran número de funcionarios y empresarios detenidos y procesados, la mayaría de los cuales ha optado por el régimen del imputado colaborador o arrepentido.

Estos hechos han superado en intensidad y gravedad a la descarnada imagen en la cual se observa en un video a José López, secretario de Obras Públicas del kirchnerismo, en el momento en que arrojaba bolsos con nueve millones de dólares para hacerlos ingresar a un convento a través de sus muros, suceso que, a la vez, contó con la complicidad de las monjas de dicha institución religiosa, en junio de 2016; el mismo funcionario portaba un arma larga de alto calibre.

¿Cómo caracterizar estas conductas corruptas de un grupo de gobernantes y funcionarios que durante doce años mantuvieron en sus manos el control del Estado? En la historia argentina del siglo XX, al menos, no se había configurado nunca una situación semejante. Este entramado de corrupción se llevó a cabo mediante un sistema institucional que he calificado de Estado faccioso, a falta de una denominación mejor ${ }^{2}$. El Estado faccioso es la expresión de la corrupción organizada y sistemática que ha condicionado la vida cotidiana por la forma en que se saquearon los recursos públicos, a través del enriquecimiento ilícito de funcionarios del más alto nivel, de dirigentes políticos, jueces y empresarios. No se trata, como veremos, de un Estado mafioso, capturado por la mafia, sino de un grupo faccioso de gobernantes que se organiza desde la cumbre del poder político para efectuar una facturación propia de las arcas públicas.

La democracia argentina convive con signos contradictorios, que ilusionan y decepcionan, la nuestra es una democracia a medio hacer. En ella sobresalen la violencia, una justicia que llega tardíamente, la sensación de impunidad, el estancamiento económico, las desigualdades múltiples, la falta de estímulo, el sentimiento de decadencia. Los hechos de corrupción del período kirchnerista emergen a luz de una manera brutal y literal ha dejado estupefacta a la ciudadanía. La corrupción sistémica organizada y reproducida desde redes institucionales atenta contra los principios y valores éticos de cualquier sociedad.

${ }^{2}$ Hugo Quiroga, La democracia que no es. Politica y sociedad en la Argentina (1983-2016), Buenos Aires, Edhasa, 2016.

Araucaria. Revista Iberoamericana de Filosofía, Política, Humanidades y Relaciones Internacionales, año 20, $\mathrm{n}^{\circ} 40$. Segundo semestre de 2018. Pp. 233-257. ISSN 1575-6823 e-ISSN 2340-2199 doi: 10.12795/araucaria.2018.i40.10 
Nuestro universo de referencia será, entonces, la democracia argentina en su trama de corrupción, con todo lo que tiene de común -y de distintocon respecto a otros regímenes democráticos de Latinoamérica y Europa. El régimen de preguntas cambió en los últimos años. Las respuestas nos llevan a pensar el presente -el mundo común-desde viejas y nuevas categorías. En el trasfondo de esta discusión asoman ciertos nudos teóricos y prácticos con los que enfrentamos al problema democrático arraigado en la corrupción. Desde la instauración democrática en 1983 se pueden distinguir dos formas diferentes de corrupción en la cumbre del poder, de mecanismos y de situaciones específicas de las prácticas corruptas que engendraron dos especies distintas de corrupción, reflejo de las conductas deshonestas de los actores públicos. El gobierno de Carlos Menem, de diez años de duración, y los gobiernos del matrimonio Kirchner (de Néstor Kirchner y de Cristina Fernández de Kirchner), que permanecieron 12 años en el poder. En estas dos experiencias distintas pondremos el acento en este artículo en ese entramado de corrupción institucional que llamamos Estado faccioso.

Por otra parte, lo que está en juego desde hace un largo tiempo en el escenario político argentino son dos formas de entender la democracia: una populista o mayoritaria y otra constitucional. En la teoría y en la experiencia histórica de nuestro país se han confrontado estas dos concepciones de democracia, y en el contraste entre ambas sólo en la primera pudo desarrollarse un Estado faccioso. Todo el artículo seguirá el hilo de nuestras premisas argumentales con la intención de comenzar a encontrarnos ante nuevas interrogaciones y quizás obtener algunas respuestas.

\section{Una mirada por los clásicos ${ }^{3}$}

Nadie se engaña admitiendo que la corrupción es un fenómeno contemporáneo; es una anomalía que siempre ha existido en todos los regímenes políticos. Desde la antigüedad, la corrupción de los sistemas de gobierno constituye uno de los temas recurrentes que interroga a los filósofos políticos. Así, son corruptas las formas de gobierno que Platón examina en la República 4 , en sus libros cuarto, octavo, noveno, en donde señala las diversas formas que puede "asumir el vicio" (445-c). Al describir las perturbaciones de la convivencia política concluye con las cuatro especies defectuosas:

\footnotetext{
${ }^{3}$ En este parágrafo he tomado en cuenta algunos aspectos de mi artículo "Corrupción de principios y corrupción de las instituciones. Una encrucijada para la democracia" (en Hugo Quiroga, La democracia que tenemos. Ensayos políticos sobre la argentina actual, Homo Sapiens Ediciones, Rosario, 1995.

${ }^{4}$ Platón, República (Traducción del griego por Antonio Camarero. Estudio preliminar y notas Luis Farré), Buenos Aires, EUDEBA, 1986.
}

Araucaria. Revista Iberoamericana de Filosofia, Política, Humanidades y Relaciones Internacionales, año 20, $\mathrm{n}^{\circ} 40$. Segundo semestre de 2018. Pp. 233-257. ISSN 1575-6823 e-ISSN 2340-2199 doi: 10.12795/araucaria.2018.i40.10 
la timocracia, la oligarquía, la democracia y la tiranía. Contrapone a estas organizaciones políticas reales una forma de gobierno ideal que puede recibir según los casos una doble denominación: Monarquía o aristocracia. Habiendo -dice Platón- cinco formas, como las mencionadas, de organizar la ciudad habrá cinco formas de almas en los individuos que le corresponden a aquellas.

En consecuencia, los hombres que se asemejan a esas formas corruptas de gobierno, con sus rasgos sobresalientes, son: el timocrático, arrastrado por la sed de honores; el oligárquico, movilizado por el afán de enriquecimiento; el democrático, portador de un deseo desenfrenado de libertad; el tirano, definido por el empleo sistemático de la violencia y por la búsqueda del beneficio personal y el consiguiente olvido del bien común.

Las formas de gobierno se corrompen provocando cambios en la organización política. ¿Cómo se explica ese cambio? Por las disensiones, por la discordia, en el seno del Estado. Cuando surgen las disensiones entre la clase de los auxiliares y la de los gobernantes o en cada clase contra sí misma. La transformación se produce, en fin, cuando se corrompe el principio que informa cada forma de gobierno (el honor, la riqueza, la libertad, el poder); cuando, en definitiva, prima el exceso y los desbordes.

La corrupción presenta, entonces, en Platón una dimensión sistémica y una dimensión individual, las que al estar férreamente conectadas no pueden ser separadas. A cada mala forma de gobierno le corresponde una determinada clase dirigente portadora de los mismos vicios. La ausencia de virtud conduce, por tanto, a las formas corruptas de gobierno. Hay en Platón una suerte de corrupción de principios. Quizá la justificación más influyente de la mentira política - que es expresión de una voluntad de poder-, la mentira como prerrogativa de una clase especial de élites políticas haya sido instaurada por Platón hace más de dos mil años 5 . En palabras de Platón, "es posible que nuestros gobernantes sea vean obligados a recurrir a la mentira y al engaño para bien de los gobernados..." (V, 459d). Un tópico tan complejo que se agrava en nuestros a escala universal nos pone ante la evidencia de que la democracia no elimina la corrupción.

Ubicados ya en el Renacimiento, Maquiavelo ${ }^{6}$ plantea en otros términos los clásicos interrogantes acerca de las constituciones buenas o las constituciones malas. Sin ignorar esos interrogantes, su preocupación gira en torno a la estabilidad política de los Estados. Pero la idea de estabilidad no sólo se vincula a la adopción de una u otra forma de gobierno sino también a la corrupción de las costumbres de un pueblo.

\footnotetext{
5 Sheldon S. Wolin, Democracia S.A. La democracia dirigida y el fantasma del totalitarismo invertido. Buenos Aires, Katz Editores, 1974, pp. 367-368.

${ }^{6}$ Maquiavelo, Discursos sobre la Primera Década de Tito Livio (Traducción de Luis Navarro, Notas de Miguel Saralegui), en Maquiavelo (Estudio Introductorio de Juan Manuel Forte Monge), Madrid, Editorial Gredos, 2011.
} 
Refiriéndose a la tipología clásica de las formas de gobierno advierte que todas ellas, al estar "expuestas a la corrupción", son perjudiciales, las buenas por su escasa duración y las otras por la "malignidad de su índole". De allí que, dirá Maquiavelo, un legislador prudente se inclinará por un gobierno mixto (que identifica con la República Romana) capaz de articular firmeza y estabilidad, aunque su tipo de Estado ideal estable son los simples: el principado o la república.

El centro de interés de Maquiavelo está puesto, en la Italia de su época, en la fundación o conservación de una república en una "ciudad corrompida". Fundar un Estado o reorganizarlo, en esas condiciones, sólo podía ser obra de una persona, que retuviera todo el poder en sus manos (el príncipe). La regeneración de las costumbres políticas de un pueblo solo podía nacer de las virtudes de un "hombres de bien", que contara para ese objetivo con el apoyo del pueblo. La tarea es difícil cuando las leyes y normas no alcanzan para frenar la "universal corrupción", sobre todo cuando éstas fueron diseñadas al organizarse la república y cuando los hombres eran buenos (Caps. XVII y XVIII).

El Estado corrupto, entonces, en Maquiavelo es un Estado inestable; es un Estado donde ha desaparecido la probidad de los ciudadanos, la virtud cívica, y la honradez y han decaído las costumbres. Las instituciones son dominadas por las ambiciones y los intereses de las facciones y por el egoísmo de los hombres. Pese a lo controvertido del tema el par dicotómico -vicio/virtud- está presente en los textos de Maquiavelo (aún cuando el término virtút tenga acepciones morales y no morales) con su preocupación por restaurar un gobierno ordenado en una sociedad corrompida.

Montesquieu, por su parte, distingue las formas de gobierno a partir de los principios que la inspiran, que las "hace actuar". Los principios son las "pasiones humanas" que movilizan y dan lugar a los diversos regímenes con sus respectivas clases dirigentes (Libro III, cap. I). Así, la virtud es el principio que ilumina a la república (democrática o aristocrática), el honor el que informa a la monarquía, y el temor es el "resorte" que anima al despotismo. Al indagar el principio de cada uno de los tres tipos de gobierno, insiste en la coincidencia entre las naturalezas de las cosas y la enseñanza de la historia.

Al comenzar su obra, Montesquieu define a la virtud como el amor a la patria y a la igualdad. Pero advierte que no se trata de una virtud moral ni de una virtud cristiana más bien de una virtud política. Este principio, tan absolutamente necesario en la democracia, significa "la renuncia de uno mismo, cosa que siempre resulta penosa". Por eso, la virtud política es definida como el amor a la patria y el amor a la igualdad que "afecta especialmente a

\footnotetext{
${ }^{7}$ Alberto Saoner, "Virtud y virtú en Maquiavelo" (En José M. González y CarlosThiebaut. Eds.), Convicciones politicas y responsabilidades éticas, Anthropos, Barcelona, 1990.
} 
las democracias", siendo en realidad un "sentimiento" y no un "conjunto de conocimientos" que pueden experimentar tanto los hombres comunes como los hombres de Estado (LIV, cap. V y Libro V, cap. II).

La ruina de los principios que informan a los distintos regímenes abre paso al Estado corrupto: "La corrupción de cada gobierno empieza casi siempre por la de sus principios". Con estas palabras encabeza Montesquieu el Libro VIII del Espíritu de las leyes. La democracia se corrompe cuando se pierde el sentido de la igualdad, pero también cuando se adquiere el sentido de la igualdad extrema ("cada uno quiere ser igual a aquellos a quienes eligió para gobernar"). En consecuencia, la democracia tiene que evitar dos excesos: el espíritu de desigualdad, que desemboca en la aristocracia o en el gobierno de uno solo, y en el espíritu de la igualdad extrema, que conduce al despotismo (Libro VIII, cap. II). No existe, finalmente, en Montesquieu otra forma de corregir la corrupción que aquella que recurre a los principios. Todo lo demás es inútil o supone un nuevo mal.

\section{Modalidades de la corrupción democrática}

¿Por qué introducimos algunos autores clásicos en un debate tan contemporáneo y además prácticamente circunscripto a la Argentina? Porque la lección de los clásicos nos ha enseñado que existen gobiernos corruptos y gobierno buenos, sanos, (aunque haya en éstos algún grado de corrupción); también porque la corrupción puede adquirir un carácter sistémico, estructural, o individual; asimismo, porque la corrupción se adhiere a las instituciones y porque el espíritu público se corrompe. Sabemos que la desviación de la conducta de los funcionarios públicos es tan antigua como la existencia misma de los Estados. Es un flagelo que arruina las instituciones y desvía la conducta de los hombres, que no son precisamente virtuosos. Más allá de los diferentes grados de corrupción, es conocido que se convive con ella, y que la disparidad, entre ayer y hoy, radica en el alto nivel de corrupción y en el grado de politización y rechazo que despierta en la sociedad. El debate sobre el "buen" gobierno, sobre sus fines, forma parte de uno de los temas emblemáticos de la discusión política actual que se esparce en todos lados.

En relación con las sociedades democráticas contemporáneas podríamos distinguir, como lo hicieron los autores clásicos, entre gobiernos honestos y gobiernos corruptos; para diferenciar si ello fuera posible entre la corrupción antigua y la corrupción moderna. Para poder conectar el tema de la corrupción con la esfera de las instituciones y con la práctica política en la realidad actual, vamos a ensayar una conceptualización de este fenómeno. La corrupción es, en términos muy sencillos, el uso indebido de un cargo público para conseguir 
beneficios personales. Prevalece siempre en la corrupción un intercambio; se cambia riqueza económica por influencia, servicios, favores, apoyos, oportunidades de negocios. En el acto de corrupción se comunican en el plano de la ilegalidad la esfera pública con la esfera privada; el funcionario hace entrega de "algo", que sólo puede obtener mediante el ejercicio de un cargo público, recibiendo como contrapartida riquezas -de un particular o de una empresa privada- en beneficio personal.

En otras palabras, es la utilización ilegítima de la esfera estatal para obtener beneficios personales. Pero, a la vez, quien corrompe influye ilegalmente en el ámbito de las decisiones públicas. Es la doble dimensión del mismo ser. Tal vez el grado mayor de corrupción que pueda exhibirse en una sociedad quede de manifiesto en la constitución de un Estado "neopatrimonialista" que confunde la esfera pública con la privada. En esta configuración ya no estaríamos delante de un Estado moderno. En la Argentina, el caso de la provincia de Catamarca, bajo el dominio de la familia Saadi durante los años ochenta del siglo XX, o el reinado de la familia Juárez durante cincuenta años en la provincia de Santiago del Estero, o de la provincia de San Luis, con los hermanos Rodríguez Sáa (que permanecen todavía en el poder), podrían servir de ejemplos contemporáneos de neopatrimonialismo, de confusión entre propiedad y gobierno o, mejor aún, de un uso privado de bienes públicos.

Sin que la administración de Menem haya llegado a constituir una verdadera cleptocracia ${ }^{8}$, lo cierto fue que la corrupción se encontró organizada en la cúpula del Gobierno, favoreciéndose políticas que transfirieron al máximo los recursos públicos en beneficio personal. Menem controlaba el Estado pero no toda la actividad económica. Las privatizaciones y la desregulación de los mercados, más allá de que fueron el resultado de la imposición de las nuevas condiciones internacionales, generaron nuevas oportunidades de corrupción. De esta manera, el flagelo se instaló en el Estado y en sus principales instituciones: el poder ejecutivo, el legislativo y el judicial. Por consiguiente, la corrupción generalizada y arraigada es una forma de disfunción de los regímenes políticos. Día tras día las instituciones fueron corroídas por dentro, y en razón de ello se abrió una zona de alto riesgo. La cara más escandalosa de la corrupción apareció con los usos de la mafia de ciertos empresarios (por ejemplo, Alfredo Yabrán ${ }^{9}$ ), de funcionarios gubernamentales, de miembros del Poder Judicial,

8 Sobre esta noción véase Susan Rose-Ackerman, La corrupción y los gobiernos. Causas, consecuencias y reformas, Madrid, Siglo XXI, 2001.

9 El empresario Yabrán, que amasó una fortuna inexplicable en veinte años guardó una relación profunda y generosa con la cumbre del menemismo. Mantuvo también excelentes vínculos con hombres del partido radical. Su influencia sobre el poder se puso de manifiesto en sus conexiones con ministros, secretarios de Estado, jueces, legisladores y sectores policiales. Con un patrimonio calculado en 3.000 millones de dólares vivió rodeado de un gigantesco sistema de seguridad hasta que puso fin a su vida para escapar de la justicia en el mes de mayo de 1990, tras ser acusado de la muerte del periodista José Luis Cabezas. El gobierno de Menem le ofreció su protección: fue recibido con 
de las fuerzas de seguridad, cuya trama de poder ha calado en lo más hondo de las instituciones argentinas. Tal vez ese poder, que se incrustó en el interior de las instituciones estatales, sea un producto reciente de la historia argentina, pero en todo caso la gravedad del fenómeno reclamó en su momento urgentes respuestas políticas ante acontecimientos que se sucedieron con inusitada rapidez. En esa trama, el gobierno de Carlos Menem se alejó lo suficiente de la imagen de un gobierno abierto y transparente.

La corrupción describe, entonces, una relación ilegal entre el Estado y el sector privado. En efecto, analizando la situación de la Argentina, cuando la corrupción gana espacio en las instituciones políticas, instalándose en gran escala y de manera prolongada, se crea una forma de relación peculiar entre el Estado (con sus funcionarios) y las corporaciones. El puente que los une es un medio ilegítimo llamado corrupción. Convergen, de esta manera, un conjunto de situaciones, hábitos y prácticas deformadas, que abren paso a una cultura de la asistencia. El Estado pasa a ser un campo de batalla donde se enfrentan los grupos de intereses por la distribución del excedente, presionando o corrompiendo a los funcionarios para defender sus intereses particulares y torcer las intenciones oficiales. De tal modo, nace en la esfera del poder económico un empresariado asistido, subvencionado, habituado a las franquicias y a los privilegios, y en la esfera pública una modalidad estatal subsidiaria. Aquí aparece la fase sistémica del problema.

El capitalismo subsidiado, que funcionó con esas características hasta fines de los ochenta, fue una fuente permanente de corrupción. Para un empresariado subvencionado es más redituable tener una estrecha relación con el poder político que competir en el mercado. En este terreno, la disputa entre los sectores empresariales se plantea más en la ascendencia que pueden conquistar en el sistema decisional que en la búsqueda de mayor competitividad y productividad. Es una lucha, pues, por asegurar su posición de negociadores con el gobierno.

La ausencia de un empresariado innovador, schumpeteriano, quedó reflejada en la opinión de Emilio Cárdenas, presidente de la Asociación de Bancos de la República Argentina y directivo del Bank of New York, vertida en un reportaje ${ }^{10}$ :

"En el sistema hipercorrupto [hablando del caso argentino] todos los valores económicos se distorsionan y prácticamente no hay mercados, ya que el empresariado va a ganar más en función de su relación con algunos centros de poder que por una conducta optimizadora".

todos los honores en la Casa de Gobierno por el Jefe de Gabinete, Jorge Rodríguez, cuando pesaba sobre él la acusación judicial. Menem tomó distancia por las repercusiones negativas que le traía esa relación, tanto a nivel nacional como internacional. Washington se interesaba en Yabrán por las firmes sospechas de lavado de dinero. Además de los oscuros negocios, para los argentinos Yabrán era el responsable intelectual del asesinato de Cabezas.

${ }^{10}$ Entrevista de Matellanes para Cash, Suplemento Económico del diario Página 12, 5/7/92.

Araucaria. Revista Iberoamericana de Filosofia, Política, Humanidades y Relaciones Internacionales, año 20, $\mathrm{n}^{\circ} 40$. Segundo semestre de 2018. Pp. 233-257. ISSN 1575-6823 e-ISSN 2340-2199 doi: 10.12795/araucaria.2018.i40.10 
Encontramos aquí una causa estructural, sistémica, de la corrupción. Por eso, en otro pasaje del reportaje, Cárdenas dio a conocer su experiencia con respecto al Estado:

"La visión que yo obtuve a través de mi trabajo es que un empresario que hace negocios con el Estado argentino no puede dejar de coimear. Si esto es así, si la coima es una condición para la existencia de la empresa, ningún código de ética la va a parar".

También existen causas de otro orden, que tienen que ver con la moral pública. Aludimos a una clase de corrupción ya mencionada que $\operatorname{Aron}^{11}$ designa con el nombre de "espíritu público" que se materializa cuando los representantes de los ciudadanos se ocupan de su propio juego olvidándose de los problemas de la sociedad, lo que ataca al corazón mismo de la democracia. La descomposición del espíritu público resulta, por tanto, del funcionamiento de las propias instituciones, de sus deficiencias y debilidades, así como también de la misma cultura política de la sociedad. Es la corrupción de principios que describía Montesquieu. Se corrompe la conducta de los funcionarios y se traiciona al "servicio público". En este sentido, vale la pena recordar a Bourdieu ${ }^{12}$ que cita a un autor alemán que escribía sobre el antiguo Egipto: "Él muestra (dice Bourdieu) cómo, en una época de crisis de confianza en el Estado y en el bien público, se veían florecer dos cosas, en los dirigentes, la corrupción $\mathrm{y}$, en los dominados, la religiosidad personal asociada con la desesperación respecto de los recursos temporales". Algo de esto sucedió en la Argentina de los años noventa: descenso en el interés por los asuntos públicos, desconfianza en la clase política (reprochada por corrupción) y un crecimiento notable de las religiones no tradicionales.

La corrupción prospera, además, en aquellos países semejantes a la Argentina que carecen de tradición democrática firme. El sistema político pretoriano, vigente entre 1930 y 1983, no permitió la estructuración de un verdadero sistema de partidos. En nuestra argumentación hay dos conceptos que se encuentran muy vinculados: el sistema político y el sistema de partidos. Pero esta ecuación se completa con un tercer término: la alternancia del poder, que sólo fue posible en las elecciones nacionales de 1989 y 1999 (más tarde aconteció la de diciembre de 2015). Pretorianismo, escasa competencia entre partidos y rotación del poder entre civiles y militares caracterizó a la vida política argentina entre 1930 (fecha del primer golpe de Estado) y 1983.

Hay situaciones especiales en la vida de una sociedad que estimulan la corrupción. Ella suele aflorar más abiertamente y rozar las más altas esferas del

\footnotetext{
${ }^{11}$ Raymond Aron, Démocratie et totalitarisme, Folio-Essais, Paris, 1990, Cap. IX.

${ }_{12}$ Pierre Bourdieu, entrevista de Roger Pol Droit y Thomas Ferenczi, Suplemento Cultura y Nación, de Clarín, 30/7/92.
}

Araucaria. Revista Iberoamericana de Filosofia, Política, Humanidades y Relaciones Internacionales, año 20, ${ }^{\circ} 40$. Segundo semestre de 2018. Pp. 233-257. ISSN 1575-6823 e-ISSN 2340-2199 doi: 10.12795/araucaria.2018.i40.10 
poder en momentos históricos muy determinados. En épocas de transformación económica y de cambio social del tipo que experimentó la Argentina en la década del noventa, la transición de una economía regulada a otra de libre mercado, con su implicancia de mutaciones profundas (desregulaciones, privatizaciones, apertura económica) derivadas de firmes decisiones políticas, ofreció un sinnúmero de oportunidades tentadoras para los proyectos particulares de los funcionarios. Igualmente, la proximidad del poder fue también, según los casos ya narrados, una buena ocasión para el desenfreno de la búsqueda del beneficio propio. Las metas individuales y faccionales desplazaron las metas públicas, que levantan los honestos funcionarios con conciencia del bien común.

Con este telón de fondo, el liberalismo económico ortodoxo que imperó en la Argentina menemista legitimó sus argumentos sobre la necesidad de reducir el Estado a su punto mínimo, para -entre otras cosas- aliviar a la comunidad de una fuente permanente de corrupción. La reforma del Estado fue presentada como la condición necesaria para la resolución de la crisis económica y como el medio más eficaz para eliminar las raíces profundas de la corrupción. Es decir, era la forma de eliminar aquellas prácticas antiguas y desviadas del uso indebido del poder público para obtener beneficios privados.

La década del noventa dejó una marca de corrupción en la vida política de los argentinos. Se trata más que nunca -teniendo en cuenta la situación actualde discutir el funcionamiento de las instituciones públicas y la reorganización de la democracia, en base a principios sanos y transparentes que ubiquen los intereses de la comunidad por encima de los intereses personales. En esos diez años de gobierno menemista no se crearon las condiciones necesarias para construir instituciones previsibles, especialmente en la esfera económica, con capacidad para evitar los sobresaltos que se generaron en el difícil entramado de la democracia argentina. La ética del éxito de la estabilidad de la moneda -el peso argentino amarrado por ley al dólar-no ocultó el pragmatismo de Menem, sus ambiciones hegemónicas, la concentración del poder, ni ocultó, por ende, la renuncia a las convicciones y a la ética de las intenciones.

\section{Las figuras del Estado}

Desde el momento en que democracia y representación se unieron en la modernidad, esa relación ha sido conflictiva. La representación es el punto débil de la democracia, porque la representación política supone siempre una distancia entre el representante y el representado que remite a la naturaleza de lo representado, esto es, a un cuerpo social heterogéneo.

La democracia adquiere un nuevo relieve y resulta evidente la imposibilidad de reducirla a instituciones y procedimientos. Es participación de los hombres, 
"pero no una participación necesariamente formulada en términos estrictamente políticos". ${ }^{13}$ Se trata, agregaríamos, de una participación activa que no se define necesariamente por los canales tradicionales de la política.

Por lo tanto, la democracia es expresión pública de la acción ciudadana, pero también organiza el espacio público del poder a través de instituciones y procedimiento. La democracia y el Estado de derecho regulan el espacio público político que instituye la vida colectiva. De allí el Estado democrático de derecho. Este es un Estado limitado que no puede revocar los derechos fundamentales constitucionalmente establecidos. Empero, las Constituciones son convenciones hechas por los hombres, y se pueden modificar o crear nuevas.

La democracia, entonces, es un régimen político que se basa en el libre juego de las opiniones contrarias, encuadrado en el Estado de derecho, que se legitima por la regla de la mayoría y por la Constitución. Mencionemos dos cuestiones importantes a tener en cuenta: la primera, el libre juego de la opinión pública no se realiza únicamente bajo formas parlamentarias, sino también en la calle, en Internet, en la telefonía móvil; la segunda, la democracia significa una forma de gobierno de la mayoría, pero en la cual no hay mayoría fija amurallada contra los procesos de cambio de opinión que no pueda reducirse otra vez a minoría ${ }^{14}$.

Sin duda, existe una relación circular entre el Estado y sus instituciones y la democracia. Justamente, un buen gobierno democrático depende del desarrollo de políticas públicas satisfactorias. El Estado sostiene la democracia porque es el garante de la primacía de los derechos sobre los poderes y de la provisión de bienes básicos de la sociedad. Es una entidad de naturaleza doble; es fuerza y es ley, escribió Paul Ricoeur ${ }^{15}$. Las dos figuras que representan al Estado son la bestia y el magistrado. El Estado es la fuerza que hace cumplir las decisiones de los poderes públicos y es la entidad que toma decisiones en situación de emergencia o extrema.

Asimismo, en su versión democrática, el Estado se define por el derecho antes que por el poder. El Estado de derecho es la creación de un sistema de previsibilidad que limita los excesos de los gobiernos democráticos y protege a los ciudadanos en el ejercicio de sus libertades fundamentales. Es por eso que Ricoeur insiste en que el Estado de derecho es el lado razonable del Estado, y esta función no se comprende sin la del abuso del poder. Destruido el Estado de derecho sólo queda el Estado como fuerza, sin límites jurídicos.

\footnotetext{
13 Claude Lefort, “Renacimiento de la democracia?”, en Claude Lefort, La incertidumbre democrática. Ensayos sobre lo político, Barcelona, Edición de Esteban Molina, Anthropos, p. 270.

14 R.M. MacIver, El monstruo del Estado (1942), (título original en inglés Leviatán and the people, de 1939), México, FCE. p. 70.

15 Paul Ricoeur, Política, sociedad e historicidad, Buenos Aires, Editorial docencia, pp. 57-58.
} 
Dejando de lado el lenguaje metafórico -la bestia y el magistrado, dos momentos de una misma realidad-, al contemplar el Estado argentino, se puede observar una tercera figura, el Estado faccioso. Volveré sobre el tema más abajo cuando hablemos de decisionismo democrático. Por ahora reiteramos que las facciones son grupos de poder encastrados en el Estado -gobernantes de turno, funcionarios públicos, burocracia profesional-, que crecen a sus expensas, obtienen beneficios particulares y ocultan - o pretenden ocultardiversos rostros degradantes: la corrupción, las prebendas, el clientelismo, el crimen organizado, la garantía de impunidad, los servicios de baja calidad. Son especialistas en medrar a partir del Estado.

Estas tres caracterizaciones acompañan el funcionamiento de un Estado actualmente devastado. El Estado faccioso, que ha creado un entramado mafioso, representa su lado más oscuro. Esta cara es la contraposición del interés común, del buen gobierno, del interés general. Los poderes facciosos son maneras de representar al Estado, del que disponen como instrumento para sus propios fines y poderío. Son, en fin, poderes ocultos que sobreviven sin reglas, en la ignorancia o en la ceguera, pero son lo suficientemente vigorosos como para hacer retroceder al Estado de derecho democrático, o detener o frenar sus reales funciones.

En la Argentina, como en muchos lados, el gobierno es identificado con el poder ejecutivo. Es cierto, el poder ejecutivo es un órgano central del proceso de toma de decisión, pero no es el único. En el juego democrático, la interacción entre el ejecutivo y el legislativo es fundamental a la hora de determinar el grado de superioridad de uno de ellos o el nivel de cooperación logrado. Son órganos distintos pero no están separados, están obligados a colaborar, porque ambos poderes forman parte del gobierno. Con todo, el papel decisivo recae sobre la tradición política forjada en la superioridad del ejecutivo.

Lo que ha prevalecido en la Argentina en los últimos años es una legitimidad decisionista antes que una legitimidad constitucional. Ese modo de legitimación está más interesado por el dominio de los hombres y la aplicación de la regla de la mayoría que en la plena vigencia del Estado de derecho democrático, el que plantea el nexo entre soberanía popular y normas constitucionales. El decisionismo democrático ${ }^{16}$, como práctica de gobierno, se inscribe en una concepción política extremadamente mayoritaria, en la que existe una presunción a priori de la legitimidad de la voluntad popular. Sin embargo, el poder del líder decisionista, avalado por el principio de la mayoría (y por la distorsión de la delegación independiente), no es la única fuente de legitimidad de las decisiones, porque el ejercicio de ese poder no es ilimitado y está sujeto a las reglas jurídicas que son también fuente de legitimidad del mismo.

${ }^{16}$ El tema ha sido tratado en varias obras, remito especialmente a Hugo Quiroga, La Argentina en Emergencia permanente, Buenos Aires, Edhasa, 2005.

Araucaria. Revista Iberoamericana de Filosofía, Política, Humanidades y Relaciones Internacionales, año 20, ${ }^{\circ} 40$. Segundo semestre de 2018. Pp. 233-257. ISSN 1575-6823 e-ISSN 2340-2199 doi: 10.12795/araucaria.2018.i40.10 
El decisionismo democrático se vale de la Constitución para desarrollar plenos poderes, mediante la delegación legislativa, el veto parcial y los decretos de necesidad y urgencia. En este sentido, la democracia argentina vive desde 1989 en emergencia permanente, lo que abre la sospecha de problemas estructurales. Es verdad que estos mecanismos de gobierno se desprenden del texto constitucional de 1994 (aunque se hayan aplicado con anterioridad), pero están previstos para situaciones de excepción, para hacer frente a los períodos de crisis profunda y dificultades extremas, como las vividas en 1989-1990 y 2001-2002, no para las épocas de normalidad. Cuando no existen esas situaciones fácticas, extraordinarias, no hay buenos motivos para invocar la emergencia.

Cuando se ensancha la esfera del ejecutivo se desplaza el debate público, el parlamento pierde poder y capacidad de control. Con esa práctica, los gobiernos no suspenden el Estado de derecho, como lo indicaría una perspectiva decisionista schmittiana, pero lo atenúan. Es un modo no republicano de ejercicio del poder. El decisionismo democrático no sólo es un modo de tomar decisiones. La voluntad política del líder decisionista se antepone a las instituciones y sus reglas, y a los contextos deliberativos. Se trata, pues, de una verdadera práctica de gobierno que le rinde culto al altar de los plenos poderes.

Con el gobierno de los Kirchner, en el caso argentino, si bien no se ha producido un deslizamiento hacia el autoritarismo, hay claramente, desde mi punto de vista, un Estado de derecho atenuado por la emergencia permanente. Es decir, por el uso y abuso de los poderes extraordinarios en épocas de normalidad. Quizá ahora aparezca con más nitidez la idea de que el decisionismo democrático es el derecho de mandar vertical y concentrado, que sustenta su acción política tanto en la ley como en las medidas de emergencia empleadas en épocas de normalidad. Esta práctica de gobierno esquiva los controles parlamentarios y judiciales, y únicamente se siente obligada frente al veredicto popular. Es un modo de organizar la vida pública. Por eso, decíamos en la introducción que sólo en una concepción populista o mayoritaria se conformó un Estado faccioso.

En definitiva, en el decisionismo democrático se contraponen tres configuraciones, aunque convivan en la misma entidad. Por un lado, el Estado de derecho atenuado, que es el resultado de la ampliación de la esfera del ejecutivo que se ha convertido en un sujeto legiferante. Se trata de una legalidad disminuida por circunstancias fácticas que ponen en riesgo la estabilidad de la democracia. Por el otro, un Estado faccioso, cuya misión es servirse de esta institución pública portadora de un interés colectivo -a la que va vaciando poco a poco hasta volverla impotente - tras el objetivo de fortalecer el poder de los hombres en detrimento de las instituciones democráticas. Una especie de empresarios mafiosos se constituye desde el Estado. En los hechos, se abren 
"espacios sin ley" - para decirlo con palabras de Dahrendorf-. Finalmente, el Estado coercitivo, violento, policíaco, en uso de la "fuerza física legítima".

\section{¿Cómo superar el lado oscuro del Estado?}

¿Hasta qué punto pueden convivir estas tres configuraciones?, ¿en qué medida interfiere el Estado faccioso, carente de reglas, en el Estado de derecho atenuado, o viceversa? ¿Cómo se puede superar ese lado oscuro del Estado?

Como vimos, el Estado argentino fue resignificado durante el kirchnerismo por su representación facciosa, aun cuando con anterioridad se pueden encontrar también repetidos antecedentes de corrupción. La diferencia es que durante esos años de hegemonía kirchnerista tuvo lugar la construcción de una matriz facciosa: el Estado como arma para delinquir. La vida política y las instituciones de la democracia y del Estado están siempre sujetas a cambio, en cuanto se adaptan a nuevas condiciones históricas. Pero la calidad institucional se mide también por las marcas que deja en la sociedad un sistema de poder hegemónico y faccioso. No puede haber recuperación de la democracia argentina sin la reconstitución de un Estado devastado, faccioso, que atenúa cada vez más el Estado de derecho, y que suscita, de manera constante, un ejercicio extraordinario del acto de gobernar.

La zona oscura del poder estatal requiere que el detentador del gobierno actúe al margen de los principios del derecho. Se trata de una zona esquiva, irracional, que hace entrar a la democracia en contradicción con ella misma, que nos remite a una figura en la cual la democracia está sometida a unas circunstancias y a unas necesidades que incluyen la posibilidad de invocación permanente de los poderes excepcionales.

Lo que hace el hombre a través de las instituciones es siempre incierto, pues la experiencia histórica del poder carece de certeza. La institución es una entidad dinámica, no estática, que tiende a conseguir fines determinados. Ese fin es lo que especifica su movimiento. No se reduce a un lugar, a un edificio, a funciones persuasivas y consensuales, roles sociales, esferas de actividades, sino que posee además un significado simbólico.

Más allá de reglas y costumbres, la institución es la expresión de la "condensación" de relaciones sociales, lo cual incluye relaciones de fuerza y poder. La Corona Inglesa es una institución, lo mismo que el Estado, la familia, la propiedad, el sufragio, la ciudadanía, la bandera, el soldado desconocido que descansa bajo el Arco de Triunfo como un símbolo de la victoria es una institución, etc. 
En la lógica decisionista del kirchnerismo, al limitar al parlamento como órgano de codecisión y contrapeso institucional, se ceñía la deliberación pública -ya que es sabido que sólo a través del Congreso la decisión política adquiere un carácter público-. $\mathrm{Al}$ respecto, resulta oportuno recordar que, durante doce años, los gobiernos kirchneristas contaron con mayoría parlamentaria o bien fueron primeras minorías que, en alianza con otras fuerzas, se convertían en mayoría. El resultado fue un parlamento debilitado, que no cumplía con sus funciones esenciales de control del gobierno y de legislar.

Efectivamente, un parlamento dominado habilitó los plenos poderes del ejecutivo aprobando los decretos de necesidad y urgencia, y también lo hizo a través de la delegación legislativa. En definitiva, se convirtió en una institución estática al servicio del ejecutivo. Pero como toda institución es dinámica, se puede adaptar a los nuevos tiempos en función de los cambios en las relaciones de fuerza.

El kirchnerismo puro y duro, en "resistencia", busca dinamizar ese órgano y sustraerlo de su letargo para transformarlo en un verdadero dispositivo de obstrucción de las iniciativas parlamentarias del presidente Macri. Dado que esta fuerza partidaria no gobierna en los principales distritos electorales del país -o prácticamente, en ninguno-, el cálculo político es restituirle al parlamento sus funciones clásicas para tornarlo en una pieza institucional de oposición salvaje. Es lo que se desprende las declaraciones de La Cámpora y del cristinismo en momentos en que el Congreso permanece en receso. Lo que siguió después no favoreció a un kirchnerismo desmembrado.

Un Estado asolado, como el argentino, que ha perdido las capacidades inherentes a sus funciones y que ha sido apropiado por poderes facciosos saca a la luz su atonía institucional. A la par, hay una crisis de autoridad del Estado, una crisis de la autoridad institucional. Nos referimos a un conjunto de instituciones de un poder ya establecido -la autoridad legislativa, administrativa, judicial, militar, etc.-, de ese poder que se ejerce de acuerdo con ciertas reglas que se aceptan como fundadas y justificadas en su ejercicio.

El término "autoridad" designa, pues, una institución existente encarnada en unas autoridades; esto es, en personas que ejercen el poder en nombre de la institución. Precisamente por eso se llaman autoridades constituidas. ${ }^{17}$ Aquí entramos en un terreno muy especial, en la dimensión de un Estado permisivo. La autoridad refiere al derecho de mandar, al poder de mandar; es un concepto que implica una reivindicación de legitimidad. Es un poder que descansa sobre un derecho: el derecho de mandar que, a su vez, implica tener la capacidad para hacerse obedecer. Sin legitimidad, sin la conformidad del que obedece, la autoridad se transformaría en dominación. En este punto entramos en el problema de la confianza, en el crédito que le otorgamos a quien manda.

${ }^{17}$ Paul Ricoeur, "La paradoja de la autoridad", en Ricoeur, Paul, Lo Justo 2. Estudios, lecturas y ejercicios de ética aplicada, Madrid, Trotta, 2008.

Araucaria. Revista Iberoamericana de Filosofia, Política, Humanidades y Relaciones Internacionales, año 20, $\mathrm{n}^{\circ} 40$. Segundo semestre de 2018. Pp. 233-257. ISSN 1575-6823 e-ISSN 2340-2199 doi: 10.12795/araucaria.2018.i40.10 
La primera prioridad, entonces, es fortalecer la autoridad del Estado de derecho frente a un Estado violento, arbitrario y faccioso. Esto supone la construcción de un Estado razonable, en el que el poder civil recupere su autoridad sobre la policía, la burocracia, los grupos facciosos. Esta tarea requiere, por supuesto, ineludiblemente, de la vigilancia de los ciudadanos. Vigilar el Estado para que sea el garante del cumplimiento de los derechos, y a la vez, convocarlo a la rendición de cuentas. La institucionalidad estatal garantiza nuestros derechos y con ellos avanzamos hacia la justicia social. En consecuencia, si la meta es la construcción de un Estado razonable, los actos del poder público deben ser examinados y controlados.

Recuperar el rol del Estado en la Argentina después de haber sido quebrantado y distorsionado por el kirchnerismo -a pesar de su retórica de la defensa de lo público- se convierte en la gran tarea a emprender en el futuro para que pueda cumplir las funciones que justifican su razón de ser. La democracia no sólo exige buenas instituciones, sino también buenos gobernantes que no hagan de su gestión una preeminencia del interés privado sobre el interés público. Que sean buenos servidores del Estado, no sus dueños.

Por fuera de la retórica perversamente "progresista", durante el kirchnerismo -insistimos- se naturalizaron la repartición de privilegios, el clientelismo, las prebendas y las posiciones de poder. Esto supuso un triunfo del poder hegemónico y faccioso, tras lo cual ya no se pudo disimular que la democracia y sus instituciones tambaleaban. Finalmente, éste no es otra cosa que la expresión de la voluntad de poder de un grupo que se adjudicó prerrogativas para delinquir, por el lugar institucional que ocupaba.

\section{La impunidad como presupuesto de la corrupción}

En una entrevista que le efectuaron el empresario Alfredo Yabrán en marzo de 1997 le preguntan -¿Qué es el poder?- Y Yabrán responde desde el realismo político más descarnado y reaccionario: "El poder es tener impunidad. Ser poderoso, es un ser impune, un hombre al que no le llega nada" ${ }^{\text {. }}$. En otras palabras, el poder te hace sentir intocable, y ahí el poderoso se extravía.

La atonía institucional, la pasividad del Estado, la corrupción, el clientelismo, las tendencias anómicas de la sociedad argentina pueden ser ilustradas con algunos ejemplos paradigmáticos. Se trata de situaciones que hacen perder el sentido de lo público y que afectan gravemente a la democracia. En consecuencia, se diluye la preocupación por el interés público.

\footnotetext{
${ }^{18}$ Con el recuerdo de esta pregunta y su respuesta comienza el libro del periodista de investigación Hugo Alconada Mon, La Raiz de los males, Cómo el poder montó un sistema para la corrupción y la impunidad en la Argentina, Buenos Aires, Planeta, 2018. La entrevista la publicó el diario Clarín el 16 de marzo de 1997.
} 
La marginalidad social produce desgarros en el entramado colectivo que no están exclusivamente vinculados a las desigualdades, al desempleo y sus consecuencias, sino, fundamentalmente, al narcotráfico y al crimen organizado -un fenómeno que se ha instalado en múltiples espacios pero que golpea con mayor violencia en los lugares más empobrecidos y, por lo tanto, más vulnerables-. Se pone en riesgo así la credibilidad de la democracia, sobre todo cuando prevalece la sensación de impunidad.

La reducción de la corrupción no es ajena, en fin, a la tarea de moralización de las instituciones y a la recuperación de la confianza en la clase dirigente. La resolución del problema es difícil. Según el Î́ndice de Percepción de la Corrupción que elabora Transparencia Internacional-la filial local es la ONGPoder Ciudadano-, la Argentina ocupaba, en 2015, el puesto 107 entre 168 países. Como se observa el grado de corrupción en el Estado es uno de los más elevados en el mundo.

La Argentina es un país que no deja de sorprender, por su política errática y por la sucesión vertiginosa de acontecimientos de trascendencia que ocupan la atención absoluta de los medios, en un cuadro en el cual, a cada momento, un nuevo hecho opaca al anterior. Por ejemplo, durante el kirchnerismo, en un breve período, hubo un bombardeo de los medios por las irregularidades supuestamente cometidas por Sergio Schoklender, que afectaron a la Fundación Madres de Plaza de Mayo, presidida por Hebe de Bonafini. El programa Sueños Compartidos remite a una posible estafa de 750 millones de pesos por planes de vivienda. Más tarde, en una secuencia acelerada sobrevinieron la tragedia de Once ${ }^{19}$; las declaraciones oficiales sobre Malvinas, y su enfrentamiento con Inglaterra; el escándalo de la empresa Ciccone -con todas sus derivacionesque involucraba en un supuesto caso de corrupción al entonces vicepresidente de la Nación, Amado Boudou.

En todos estos sucesos el Estado argentino tenía responsabilidades de control que no había cumplido ni cumplía con eficacia, tanto en la seguridad del transporte, como en el destino de los fondos públicos para la construcción de viviendas, como en materia energética.

Por otra parte, el escándalo de Panamá Papers, que salió a luz por intermedio del Consorcio Internacional de Periodistas de Investigación, que involucra a Presidentes, empresarios, deportistas, celebridades, que mantuvieron en secreto sus movimientos offshore, conmovió al mundo entero. En la Argentina, Mauricio Macri, y muchos otros, fue mencionado en una sociedad off shore de su padre. Ante una denuncia, el juez Sebastián Casanello inició una investigación sobre las declaraciones juradas del Presidente. En consecuencia, Macri repatrió 18 millones de pesos que declaró en Bahamas.

${ }^{19}$ Se la llama así al accidente ferroviario ocurrido en la Estación Once de Buenos en 2012 en el que fallecieron 51 personas con más de 700 heridos por el mal estado del tren, lo que dio lugar a causas de corrupción.

Araucaria. Revista Iberoamericana de Filosofia, Politica, Humanidades y Relaciones Internacionales, año 20, $\mathrm{n}^{\circ} 40$. Segundo semestre de 2018. Pp. 233-257. ISSN 1575-6823 e-ISSN 2340-2199 doi: 10.12795/araucaria.2018.i40.10 
La amarga sensación que dejan estos acontecimientos, como tantos otros, es que las soluciones o respuestas no llegan, o llegan de manera insatisfactoria, o tardíamente. Las investigaciones en los casos de corrupción no terminan nunca en condenas. La regla parece ser la impunidad y cierta desaprensión de la sociedad frente a estos hechos, en tanto el gobierno garantice niveles determinados de crecimiento y de consumo. Estas características nos conducen a pensar en el proceso de construcción de la democracia, y el modo en que, de manera ineluctable, complican la disposición de la relación entre Estado democrático de derecho y sociedad. El tema en discusión excede, por otra parte, la noción de calidad de la democracia.

Sin embargo, hay que reconocer el giro de la justicia federal que ha comenzado a activar causas y expedientes que había permanecido sin tratamiento durante años en materia de corrupción. Desde la instalación del gobierno del presidente Macri, en diciembre de 2015, inexplicablemente el comportamiento de la justicia federal es otro. Se multiplicaron y aceleraron las causas por lavado de dinero, por asociación ilícita, por enriquecimiento ilícito, que involucran a la ex presidenta Cristina Kircher, sus hijos y sus ex funcionarios, así como también a un importante grupo de empresarios.

La baja calidad de la democracia se expresa, además, a través de una clase dirigente - que incluye tanto a gobernantes como al resto de la elite política - carente de proyectos estratégicos, y que se maneja con la inmediatez de la política. La calidad de la democracia se mide también por el tipo de cultura política de los ciudadanos y sus niveles de interés por la cosa pública. Buena parte de los ciudadanos están más preocupados por la satisfacción de sus propios intereses que por el desenvolvimiento de la democracia y el fortalecimiento de sus instituciones.

El país vive un presente eterno, rodeado de instituciones débiles, donde el respeto a la división de poderes es escaso y la sensación de impunidad abundante. Esta es la forma en que se articula el vínculo entre gobernantes y gobernados. El comportamiento de la dirigencia política no está disociado del desinterés de la sociedad por ciertos procedimientos de orden institucional y ético. Según las circunstancias de tiempo y lugar, lo colectivo pasa a segundo plano. En este sentido, la dirigencia política "representa" genuinamente a la sociedad argentina. Es sabido, la cultura de la impunidad corroe el espíritu público y el edificio institucional.

El cuerpo del Estado en la Argentina está corrompido. Una de las raíces del problema es la disfuncionalidad de las instituciones públicas y privadas. La corrupción crea ineficacia y desigualdades económicas y sociales. Pero no es un fenómeno exclusivamente económico y social, está íntimamente entretejido 
con la política. La corrupción es un síntoma importante del déficit de ciertas esferas del Estado. Algo no funciona bien en la gestión de los asuntos públicos. El Estado coercitivo se desplaza en un arco que se extiende de la pasividad a la violencia extrema, y viceversa. La violencia está inscrita en la estructura misma del Estado. Existe el "rostro de la violencia de los fundadores"; por eso quizá no exista ningún Estado que no haya nacido de la violencia - de la conquista, de la usurpación, del matrimonio acordado, de las guerras-. La racionalidad tiene, pues, otra vertiente: el residuo de la violencia fundante. Hay una relación muy nítida entre política y violencia. ${ }^{20}$

En este clima de impunidad se suceden con frecuencia numerosos episodios de justicia por mano propia, llamados "linchamientos", debido a la ineficacia de las fuerzas de seguridad y a la expansión de los delitos, que revisten un carácter cada más violento. Un Estado "ausente", "pasivo", que no cumple, o lo hace de manera deficiente, con su rol de Estado coercitivo, impulsa a los ciudadanos a hacer justicia por mano propia, en una desafortunada violación de los derechos humanos.

La anomia social, entendida como el desapego total a las reglas, secciona en múltiples trozos el tejido comunitario. Las desigualdades múltiples (una de sus consecuencias es la pobreza extrema) y el fastidio de la vida cotidiana (inseguridad, cortes de luz, problemas de infraestructura) acompañan la ira de los manifestantes. Las situaciones anómicas están asociadas, igualmente, a la sensación de impunidad que se percibe por los hechos de corrupción ocurridos tanto en la cumbre como en la base.

En las relaciones entre el estado de anomia social y la comisión de delitos -que se han incrementado notoriamente-, cabe centrar la atención en la anomia institucional que prevalece en los organismos administrativos responsables de preservar la seguridad. ${ }^{21} \mathrm{El}$ dilema de la anomia nos traslada a la capacidad de un gobierno para implementar un plan de obra, una reforma, en una sociedad impregnada de la inacción del sistema institucional y administrativo.

Por todos estos motivos, necesitamos de un Estado de derecho razonable y equilibrado - la cara opuesta de un Estado coercitivo-, para que los conflictos sociales y políticos no se resuelvan por la vía de la violencia. La política democrática es la gestión pacífica de los conflictos, su regulación y administración mediante las instituciones. Resume, en fin, la búsqueda de compromisos. Se trata, pues, de llevar a cabo del difícil arte de vivir juntos en una comunidad política.

\footnotetext{
${ }^{20}$ Paul Ricoeur,'Le paradoxe politique" (texto de 1957), en Ricoeur, Histoire y vérité, Paris, Seuil, 1964.

${ }^{21}$ Ricardo Sidicaro, "Las anomias argentinas", en Apuntes .Buenos Aires, CECYP, No 26, pp. 120-134.
} 


\section{Reflexión final}

La legitimidad de un orden democrático depende fundamentalmente del apoyo de los ciudadanos y del rol de los partidos políticos. La corrupción en escalas muy elevadas, se transforma en un factor de deslegitimación de la democracia. Los escándalos políticos, como los comentados ejemplos de Brasil y de Argentina (Lava Jato y los "cuadernos gate"), contribuyen a deslegitimar a los dirigentes políticos, a los partidos y a las instituciones públicas. La percepción generalizada de corrupción, corroborada o no en los tribunales, acentúa la crisis de credibilidad y fortalece la desconfianza colectiva en los políticos, abriendo espacio a las deslealtades al sistema. Las instituciones políticas tienen dimensiones tanto morales como estructurales, y entre la cultura de la sociedad y las instituciones de la política hay siempre una estrecha relación, de carácter dialéctico.

La corrupción tolerada o insuficientemente combatida a nivel de la estructura estatal amenaza, pues, al sistema político y debilita las instituciones, mientras se favorecen los intereses económicos particulares de los individuos o de los grupos. En general, el grado de corrupción aumenta a medida que se asciende en la jerarquía burocrática o política. Tal modelo de corrupción en la cumbre manifiesta un nivel muy bajo de institucionalización política ${ }^{22}$. Si las instituciones son débiles la sociedad verá reducida su capacidad para contener las codicias personales de los funcionarios. Por tanto, éstos antepondrán con más facilidad su interés particular al interés general. La Argentina, como otros países de América Latina, bien podría quedar encasillada en ese modelo.

De las experiencias concretas y de las enseñanzas de los autores clásicos y contemporáneos se pueden inferir tres resultados. En primer lugar, la corrupción tiene una fase sistémica y otra individual. Involucra no sólo al sistema mismo, al Estado, a las instituciones, sino también a los individuos. El comportamiento de éstos puede deformar el "espíritu público" y generar una cultura de corrupción. En segundo lugar, con instituciones corruptas las democracias no pueden ser estables. La corrupción pone en peligro, pues, la perdurabilidad de los regímenes democráticos. En tercer lugar, la virtud política es un recurso esencial para el buen funcionamiento de la democracia. La virtud, que prima sobre la fuerza, las pasiones y los intereses privados, está llamada a jugar un papel importante en la consolidación de la democracia.

Con razón aseveraba Raymond Aron"23: "La opinión que los ciudadanos se forjan de su régimen es inseparable de las cualidades defectos del mismo". Las encuestas, y la calle, registraron como vimos la creencia de los argentinos en

${ }^{22}$ Samuel P. Huntington, El orden politico en las sociedades de cambio, Paidós, Buenos Aires, 1990.

${ }^{23}$ Raymon Aron, Démocratie et totalitarisme, Ob. Cit.

Araucaria. Revista Iberoamericana de Filosofía, Política, Humanidades y Relaciones Internacionales, año 20, $\mathrm{n}^{\circ} 40$. Segundo semestre de 2018. Pp. 233-257. ISSN 1575-6823 e-ISSN 2340-2199 doi: 10.12795/araucaria.2018.i40.10 
los altos niveles de corrupción, lo que podría tener derivaciones peligrosas para la estabilidad de la democracia. El problema se agrava porque el poder judicial, encargado de esclarecer los hechos, quedó bajo sospecha, lo que generó dudas sobre la posibilidad de conocer la verdad y sancionar a los culpables. La desconfianza colectiva en los políticos, funcionarios y magistrados abona un terreno fértil para las deslealtades al orden democrático.

De nuevo, ¿cómo controlar la corrupción que obedece tanto a comportamientos individuales como estructurales? La resolución del problema es difícil. ¿Cómo lograr que los funcionarios y los representantes de los ciudadanos recuperen la moral pública y la virtud cívica, con instituciones corruptas y cuando predomina la incredulidad colectiva sobre sus quehaceres? El desafío es aún mayor. Una respuesta posible es la que proviene de la apelación a la moral pública y la virtud republicana. Tal vez convenga recordar las palabras de Montesquieu: "la corrupción de cada gobierno comienza casi siempre por la de sus principios". La virtud politica es el principio de la democracia. No parece, por cierto, un mal punto de partida. 


\section{Referencias bibliográficas:}

Alberto Saoner, "Virtud y virtú en Maquiavelo" (En José M. González y CarlosThiebaut. Eds.), Convicciones politicas y responsabilidades éticas, Anthropos, Barcelona, 1990.

Claude Lefort, La incertidumbre democrática. Ensayos sobre lo político, Barcelona, Edición de Esteban Molina, Anthropos, 2004.

Dennis F. Thompson, La ética política y el ejercicio de cargos públicos, Barcelona, Gedisa, 1999.

Francisco Laporta y Silvina Álvarez (eds.), La corrupción política, Alianza, Madrid, 1997.

Giulio Sapelli, Cleptocracia. El "mecanismo único" de la corrupción entre economía y política, Buenos Aires, Losada, 1998.

Hugo Alconada Mon, La Raíz de los males, Cómo el poder montó un sistema para la corrupción y la impunidad en la Argentina, Buenos Aires, Planeta, 2018.

Hugo Quiroga, La democracia que tenemos. Ensayos políticos sobre la argentina actual, Homo Sapiens Ediciones, Rosario, 1995.

Hugo Quiroga, La Argentina en Emergencia permanente, Buenos Aires, Edhasa, 2005.

Hugo Quiroga, La democracia que no es. Política y sociedad en la Argentina (1983-2016), Buenos Aires, Edhasa, 2016.

Jorge F. Malem Seña, La corrupción. Aspectos éticos, económicos, políticos y jurídicos, Gedisa, Barcelona, 2002.

Joseph Raz, La ética en el ámbito público, Barcelona, Gedisa, 2001.

Manuel Villoria Mendieta, La corrupción política, Madrid, Editorial Síntesis, 2006.

Maquiavelo, Discursos sobre la Primera Década de Tito Livio (Traducción de Luis

Navarro, Notas de Miguel Saralegui), en Maquiavelo (Estudio Introductorio de Juan Manuel Forte Monge), Madrid, Editorial Gredos, 2011.

Montesquieu, Del espiritu de las leyes, (Traducción de Mercedes Blázquez y Pedro de Vega), Tecnos, Madrid, 1982.

Paul Ricoeur, Histoire y vérité, Paris, Seuil, 1964.

Paul Ricoeur, Lo Justo 2. Estudios, lecturas y ejercicios de ética aplicada, Madrid, Trotta, 2008.

Peter Eigen, Las redes de la corrupción. La sociedad civil contra los abusos del poder, Barcelona, Planeta, 2004.

Platón, República (Traducción del griego por Antonio Camarero. Estudio preliminar y notas Luis Farré), Buenos Aires, EUDEBA, 1986. 
Raymond Aron, Démocratie et totalitarisme, Folio-Essais, Paris, 1990.

Robert Klitgaard, Controlando la corrupción. Una indagación práctica para el gran problema social de fin de siglo, Buenos Aires, Sudamericana, 1994.

Samuel P. Huntington, El orden político en las sociedades de cambio, Buenos Aires, Paidós, 1990.

Sheldon S. Wolin, Democracia S.A. La democracia dirigida y el fantasma del totalitarismo invertido. Buenos Aires, Katz Editores, 1974.

Susan Rose-Ackerman, La corrupción y los gobiernos. Causas, consecuencias y reformas, Madrid, Siglo XXI, 2001. 
